\title{
The Evolving Nature of Hepatic Abscess: A Review
}

\author{
Marianna G. Mavilia*1, Marco Molina ${ }^{2}$ and George Y. Wu ${ }^{3}$ \\ ${ }^{1}$ University of New England College of Osteopathic Medicine, Biddeford, ME, USA; ${ }^{2}$ Department of Radiology, UCONN Health, \\ Farmington, CT, USA; ${ }^{3}$ Department of Medicine, Division of Gastroenterology-Hepatology, UCONN Health, Farmington, CT, USA
}

\begin{abstract}
Hepatic abscess (HA) remains a serious and often difficult to diagnose problem. HAs can be divided into three main categories based on the underlying conditions: infectious, malignant, and iatrogenic. Infectious abscesses include those secondary to direct extension from local infection, systemic bacteremia, and intra-abdominal infections that seed the portal system. However, over the years, the etiologies and risks factors for HA have continued to evolve. Prompt recognition is important for instituting effective management and obtaining good outcomes.

(C) 2016 The Second Affiliated Hospital of Chongqing Medical University. Published by XIA \& HE Publishing Inc. All rights reserved.
\end{abstract}

\section{Introduction}

Hepatic abscess (HA) can be defined as an encapsulated collection of suppurative material within the liver parenchyma, ${ }^{1,2}$ which may be infected by bacterial, fungal, and/ or parasitic micro-organisms. ${ }^{2}$ Since the majority of HAs in the Western world are infected with bacteria, ${ }^{2,3}$ pyogenic liver abscess will be the focus of this review.

In the early 1900s, the most common cause of HA was pylephlebitis secondary to appendicitis. ${ }^{4}$ In the late $1900 \mathrm{~s}$, biliary tract disease emerged as the most frequent culprit, ${ }^{4,5}$ and it remains the most common cause of HA today. $2,6,7,8$ More recently, there has been an increase in the incidence of $\mathrm{HA}$ arising in association with malignancies and their treatment, including HA from liver metastasis ${ }^{4,9}$ and as complications of transarterial chemoembolization (TACE) or radiofrequency ablation (RFA). ${ }^{10-14}$

Although the frequency of HA varies by region, ${ }^{15}$ the overall incidence is fairly low, ranging from 2.3 cases per 100,000 hospital admissions in North America ${ }^{15}$ to 275.4 per 100,000

Keywords: Liver abscess; Liver neoplasms; Iatrogenic disease; Risk factors. Abbreviations: ALP, alkaline phosphatase; ALT, alanine aminotransferase; AST, aspartate aminotransferase; CEUS, contrast-enhanced ultrasound; $C T$, computed tomography; DM, diabetes mellitus; EBA, enterobiliary anastomosis; FDA, Food and Drug Administration; GGT, gamma glutamyl transpeptidase; HA, hepatic abscess; HCC, hepatocellular carcinoma; INR, international normalized ratio; IV, intravenous; MRI, magnetic resonance imaging; PD, percutaneous drainage; PMN, polymorphonuclear leukocyte; PO, oral, PPI, proton pump inhibitor; RFA, radiofrequency ablation; $S D$, surgical drainage; TACE, transarterial chemoembolization; US, ultrasound; WBC, white blood cell count.

Received: 18 January 2016; Revised: 25 February 2016; Accepted: 09 March 2016 DOI: $10.14218 /$ JCTH.2016.00004.

*Correspondence to: Marianna G. Mavilia, University of New England College of Osteopathic Medicine, 11 Hills Beach Road, Biddeford, ME 04005, USA. Tel: +1-617-435-1185, Fax: +1-860-679-6582, Email: marimavilia@gmail.com in Taiwan. ${ }^{16}$ In the early 1900 s, mortality was as high as $75 \%-80 \%,{ }^{4}$ while today, mortality is markedly decreased, ranging from $10 \%-40 \% .^{8}$ This is due to improvements in antibiotic therapy and interventional procedures for the treatment of $H A .^{3,4,6}$

Although mortality is improved, it is still high, making early diagnosis of HA exceedingly important to the clinical outcome. $\mathrm{HA}$ can be difficult to diagnose, and the symptomatology is variable. Often, objective findings are nonspecific, ${ }^{16,17}$ and therefore, diagnosis relies largely on imaging. ${ }^{2}$

The aim of this review is to describe some of the changes in important risk factors, mechanisms, and patterns of development of HA and to review the current recommendations for the diagnosis and treatment of this condition.

\section{Risk Factors}

There are many risk factors associated with the development of HA and increased mortality from HA. These factors are detailed in Table 1 . Risk factors predisposing patients to HA range from diabetes mellitus (DM), cirrhosis, general immune-compromised state, use of proton pump inhibitor (PPI) medications, gender, and age.

DM is a predisposing factor for HA that is well documented in the literature. ${ }^{5,18,19}$ Studies have found DM as a concomitant disease in $29.3 \%-44.3 \%$ of patients with HA. ${ }^{5,19}$ Diabetic patients are also more likely to present with multiple abscesses. ${ }^{19}$ There are several pathophysiologic features of DM that contribute to higher infection risk. ${ }^{18,20}$ For instance, hyperglycemia is known to alter neutrophil metabolism. ${ }^{21}$ Diabetics also have been shown to have impaired polymorphonuclear leukocyte (PMN) chemotaxis and phagocytosis, ${ }^{18,20}$ which weakens their immune defense against infections and leaves them more susceptible to abscess formation.

Like diabetics, patients with liver cirrhosis have an increased risk of $\mathrm{HA}$ due to their immune-compromised state. $^{7}$ Cirrhotics are 15.4 times more likely to develop HA than the general population. ${ }^{7,22}$

Other conditions and treatments may compromise the immune system and render it inadequate to counteract pathogens. These include various immunodeficiencies, chemotherapy, solid malignancies, immunosuppression therapy after organ transplant, ${ }^{20}$ as well as splenectomy, ${ }^{23}$ all of which have been associated with an increased risk of HA.

The use of PPI medications has also been found to increase the risk of HA formation. ${ }^{24}$ This is presumably because PPI medications increase the gastric $\mathrm{pH}$, which decreases the natural gastric defense against bacteria. ${ }^{24}$ In a large case-control study, Wang et al. demonstrated a doseresponse relationship between HA formation and dose of PPI over a 90 day period. ${ }^{24}$ Although this was a large study, 
Table 1. Risk factors for development of hepatic abscess (HA) and increased mortality from HA

\begin{tabular}{|c|c|}
\hline $\begin{array}{l}\text { Increased risk of } \\
\text { developing } \mathrm{HA}\end{array}$ & $\begin{array}{l}\text { Increased mortality } \\
\text { from HA }\end{array}$ \\
\hline Diabetes mellitus $* 5,8,19$ & Malignancy $^{16}$ \\
\hline Liver cirrhosis ${ }^{* 22}$ & Diabetes mellitus ${ }^{* 5,16}$ \\
\hline $\begin{array}{l}\text { Immune-compromised } \\
\text { state }^{20}\end{array}$ & Liver cirrhosis $^{* 22}$ \\
\hline Use of $\mathrm{PPI}^{24}$ & Male gender ${ }^{* 16}$ \\
\hline Advanced age ${ }^{19}$ & Multiorgan failure ${ }^{16}$ \\
\hline \multirow[t]{8}{*}{ Male gender ${ }^{* 16}$} & Sepsis $^{5}$ \\
\hline & $\begin{array}{l}\text { Infection with mixed } \\
\text { organisms }\end{array}$ \\
\hline & HA rupture ${ }^{16}$ \\
\hline & Abscess size $>5 \mathrm{~cm}^{5}$ \\
\hline & Respiratory distress ${ }^{16}$ \\
\hline & Hypotension ${ }^{16}$ \\
\hline & Jaundice ${ }^{16}$ \\
\hline & Extrahepatic involvement ${ }^{16}$ \\
\hline
\end{tabular}

*Diabetes mellitus, liver cirrhosis and male gender are risk factors for both development and increased mortality of $\mathrm{HA}$.

encompassing 10 years of data, it was conducted exclusively in Taiwan, where the incidence of HA in general is high. Additionally, control subjects were not matched for comorbidities or indication for PPI use. Both of these factors may have had some influence on their findings.

Most cases of HA present at advanced age. One study reported a mean age $>57$ years. ${ }^{19}$ This finding suggests that older individuals are more susceptible to bacterial infection and thus abscess formation. ${ }^{21}$ However, more research is needed to clarify the mechanism of this association.

In a 10-year audit of experience with HA from 1989 to 1999 , Lee et al. found the ratio of males to females presenting with HA was about 2 to $1 .{ }^{5}$ This was confirmed by Pang et al. ${ }^{17}$ and Lin et al. ${ }^{25}$

\section{Morbidity and Mortality}

As previously mentioned, mortality remains high, although it has decreased over time. Several associated factors and comorbid conditions have been implicated in the risk of death from HA. ${ }^{8}$ A study by Chen et al. divided a group of 134 patients with primary HA into a mortality and a survivor group and identified several risk factors for increased mortality, including male gender, malignancy, multi-organ failure, and HA rupture. ${ }^{16}$ Other signs and symptoms found to be associated with the mortality group in this study included respiratory distress, hypotension, jaundice, and extrahepatic involvement, such as endopthalmitis. ${ }^{16}$ The latter mentioned signs were indicators of higher comorbidity, which not surprisingly were associated with higher mortality in those patients. ${ }^{16} \mathrm{~A}$ similar study by Lee et al. found that diabetes, sepsis, and the presence of larger abscesses $(>5 \mathrm{~cm}$ ) were additional factors associated with higher mortality ${ }^{5}$ that were not identified as significant in the study by Chen et al. ${ }^{16}$ In contrast to that study, Lee et al. did not find a significant difference in mortality by gender. ${ }^{5}$ Although these studies were conducted in the same region and used very similar sample sizes, the difference in findings could be explained by the inclusion criteria. Chen et al. included only primary $\mathrm{HA}$, whereas Lee et al. did not specify the diagnosis as primary or secondary.

The theme of immune compromise is also seen in the mortality rates for HA. Mortality rates for HA in patients with associated malignancy was reported to be double that of cancer-free patients. ${ }^{26}$ As reported by Lin et al., patients with hepatocellular carcinoma (HCC) and HA had a higher 60-day mortality rate compared to those with HCC only. ${ }^{15}$ Additionally, cirrhosis was associated with a 4-fold increase in the risk of death from HA. ${ }^{22}$ Mortality was also reported to increase when HA contained mixed organisms or fungal infection. ${ }^{4}$

\section{Categorization}

For the purposes of this review, we have divided HA into three subgroups based on category: infectious, malignant, and iatrogenic. There are some areas of overlap between categories, as depicted in Figure 1.

\section{Infectious Abscess}

Pathogens may gain access to the liver through contiguous spread from infection of neighboring tissue, from blunt or penetrating trauma to the abdomen, 9,27 and through hematogenous spread (Fig. 2). ${ }^{2}$ The latter most commonly occurs due to systemic bacteremia or in intra-abdominal infections. However, bacteremia is only detectable in $43 \%$ of $\mathrm{HAs}^{9}$ making diagnosis of HA in this instance increasingly difficult. In cases of intra-abdominal infection, including appendicitis and diverticulitis, bacteria can seed the portal vessels, causing pylephlebitis and portal pyemia, ultimately leading to HA formation. ${ }^{6,7}$ A recent cohort study of 54,147 patients with diverticular disease and 216,588 matched controls found the incidence of $\mathrm{HA}$ to be 2.44-fold higher in those with diverticular disease compared to controls. ${ }^{28}$ This study included patients with both diverticulosis and diverticulitis. ${ }^{28}$ Of them, $10 \%-25 \%$ had diverticulitis or related complications during the 4-8 year follow-up period. ${ }^{28}$ Since diverticulitis seems more likely to cause mucosal defect or perforation than diverticulosis, the inclusion of diverticulosis patients is interesting and suggests that the incidence of $\mathrm{HA}$ in this group may have been even higher if the study had examined only diverticulitis patients. With the development of diagnostic methods to facilitate early detection and surgery to resolve the infection before spread can occur, appendicitis and diverticulitis have become much less frequent causes of HA.

Nonmetastatic colorectal cancer has also been associated with HA formation. This link is thought to be due to local destruction of the mucosa by the tumor, which allows invasion of bacteria and entry into the bloodstream. ${ }^{18,29-31}$ Similar cases have also been reported postpolypectomy, where polyp removal caused a microperforation in the colon. ${ }^{32}$ Under these circumstances, bacteria gain access to the portal venous system and then to the liver bed. ${ }^{8,20}$ In some of these cases, the HA was the presenting sign ${ }^{30}$ and has been considered to be a herald of silent colon cancer. ${ }^{5}$

Currently, the most common route of infection is the biliary tree, responsible for $30 \%-50 \%$ of cases of HA. ${ }^{7,33}$ Biliary infections occur mainly in the setting of obstruction from gallstone disease, malignancy, or stricture, ${ }^{4,6}$ leading to 


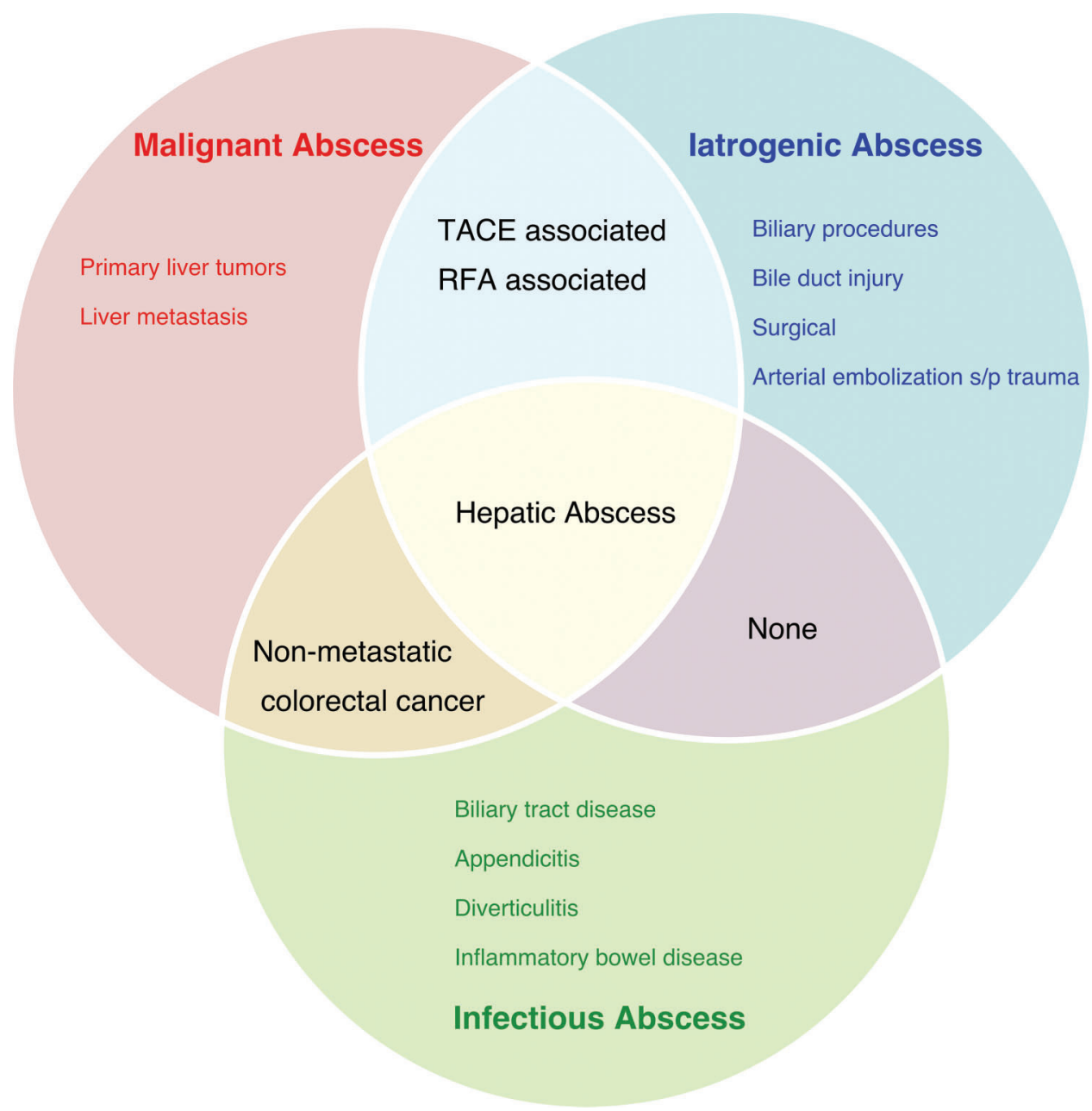

Fig. 1. The gray areas. Fig. 1 depicts a comparison of the sub-groups of $\mathrm{HA}$ and also delineates the areas of overlap between them.

proliferation of bacteria in the biliary tract, ascending cholangitis, and invasion of the liver parenchyma.

Although many types of bacteria have been identified in HAs, there have been several microbiological trends. Prior to 1980 , Escherichia coli was the most common pathogen in HA worldwide. $^{3,15}$ Currently, this trend has shifted to Klebsiella pneumonia, particularly in Asia, where it accounts for $50 \%-$ $73 \%$ of cases. $3,16,29$ This may be related to the association of HA with DM. Diabetic patients are more susceptible to K. pneumonia infections. ${ }^{19,21,34}$ Clostridium perfringens has also been reported in the literature more frequently, but it is still a rare cause of HA. ${ }^{20}$ Depending on the primary source of infection, multiple organisms can be involved in $\mathrm{HA}{ }^{9}$ Eltawansy et al. reported the presence of mixed organisms in $14 \%-55 \%$ of cases. ${ }^{20}$

\section{Malignant Abscess}

Malignant abscesses can be divided into three subcategories: secondary infection of a primary liver tumor, secondary infection of a metastatic liver lesion, and superinfection of spontaneous necrosis.

\section{Secondary infection of primary liver tumor}

Primary HCC can spontaneously develop in an area of central necrosis, ${ }^{1}$ which can become infected with bacteria. ${ }^{7,15}$ It is also possible for HCC to cause biliary obstruction, 7,15 potentially leading to ascending cholangitis and $\mathrm{HA}$, as described above.

HA can be the initial manifestation of HCC. ${ }^{15}$ These individuals tend to have a worse prognosis because the diagnosis of HA often delays the diagnosis of underlying HCC. ${ }^{15}$ Some signs that were reported to be helpful in identifying superinfected malignancy included a thickened wall, the presence of septations, aerobilia, portal thrombosis, and gas within the abscess. ${ }^{2,8}$

\section{Secondary infection of liver metastases}

HA formation from liver metastasis is quite rare. A compilation of 1,262 cases of HA over 32 different studies found that only $3 \%$ were associated with hepatic metastasis. ${ }^{9}$ However, in compiling these cases, it is possible that inclusion criteria may have differed between studies and skewed the results. There are a number of case reports of metastatic liver lesions 


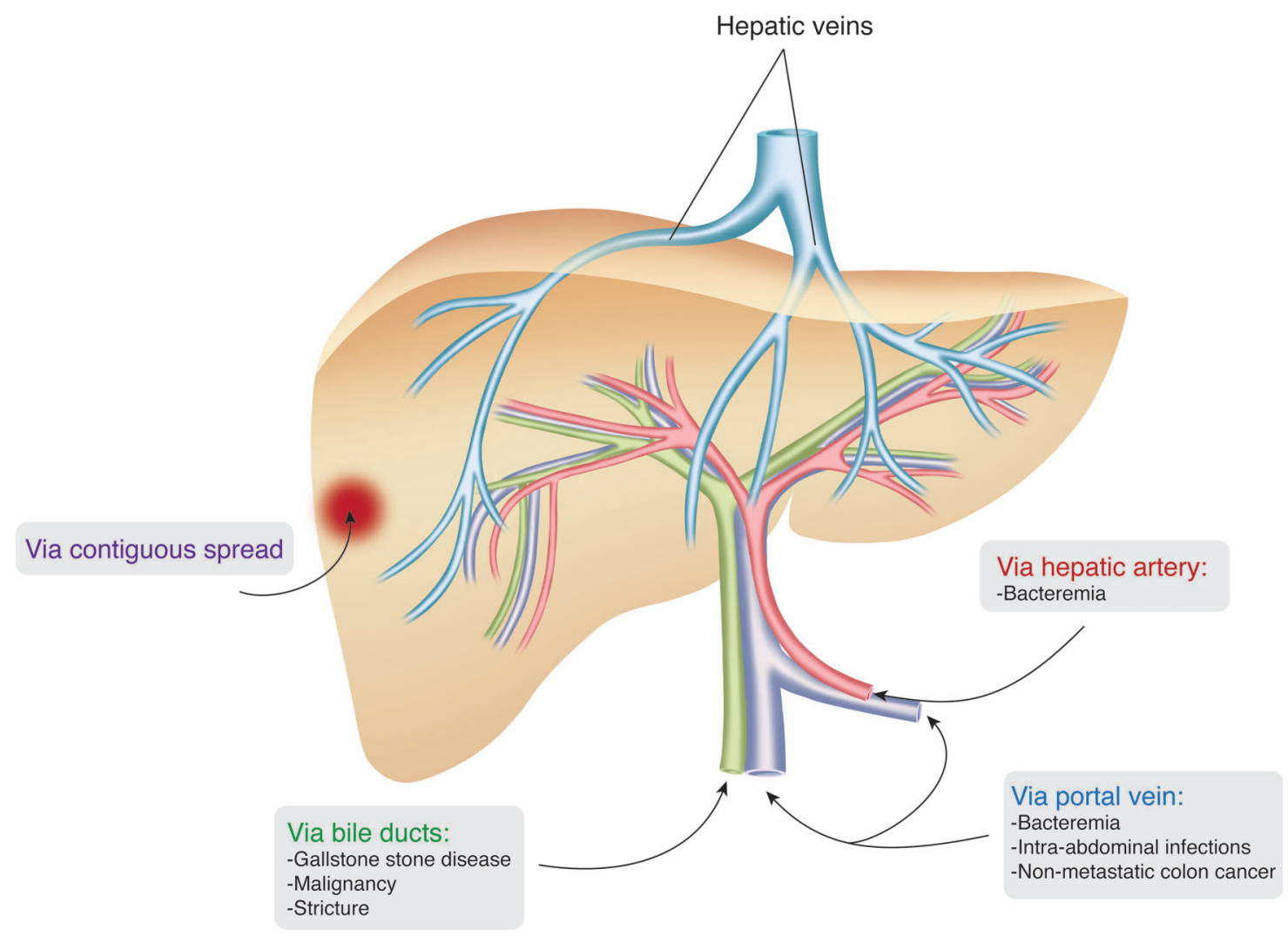

Fig. 2. Routes of infection.

arising from metastatic melanoma, ${ }^{27}$ rectal cancer, ${ }^{35}$ colon cancer $^{31,36,37}$ esophageal carcinoma, ${ }^{9,37}$ and pancreatic cancer $^{37,38}$ among others.

\section{Superinfection of spontaneous necrosis}

TACE and RFA are frequently used in the treatment of inoperable $\mathrm{HCC}^{10,11,39}$ as well as liver metastasis. Both procedures induce necrosis of the tumor and some surrounding liver tissue. This area of necrosis may serve as a nidus for infection. In addition, some mechanisms specific to the TACE procedure predispose individuals to abscess formation. For example, TACE-induced necrosis suppresses reticuloendothelial cell activity, leading to decreased immunity. ${ }^{11}$ There is also an immunosuppressant effect from the chemotherapeutic agents used. ${ }^{39}$

The incidence of $\mathrm{HA}$ has been reported to range from $0 \%$ $1.4 \%$ following TACE, ${ }^{10,11}$ and $0.1 \%-0.7 \%$ following RFA. ${ }^{12,13}$ The incidence increases in patients who have a pre-existing enterobiliary anastomosis (EBA). ${ }^{12,13}$ In these patients, a dysfunctional sphincter of Oddi allows retrograde contamination of the biliary tract, ${ }^{14}$ which occurs in $90 \%$ of patients with EBA. ${ }^{14}$ For patients with previous EBA treated specifically with RFA, the incidence of $\mathrm{HA}$ increases up to $86 \% .{ }^{12}$ For these reasons, EBA may be a contraindication for TACE and RFA. ${ }^{2}$ Given the significantly increased risk, less than $2 \%$ of patients who underwent RFA had pre-existing EBA in a large study by Elias et al. ${ }^{13}$ Interestingly, this same study demonstrated that when EBA and RFA were done at the same time, there was no increased risk for HA formation. ${ }^{13}$ However, this was a very small subgroup of the study with only four patients. In these four patients with RFA and EBA performed at the same time, no patients developed $\mathrm{HA}$, presumably because peri-operative antibiotic coverage prevented biliary contamination and $\mathrm{HA}$ formation. ${ }^{13}$

Although the overall incidence of HA following TACE and RFA is low, the impact is increasing because of the increased use of ablative techniques for HCC palliation ${ }^{39,40}$ and the increase in incidence of $\mathrm{HCC}{ }^{41}$

Given the known risk of HA in this situation, the effect of antibiotic prophylaxis for both TACE and RFA has been studied, but its role remains controversial. ${ }^{10,13}$ Currently, there are no guidelines for prophylaxis before or during TACE. ${ }^{10}$ Hoffman et al. found that only one out of the 10 patients with prior EBA undergoing RFA treatment developed HA after antibacterial prophylaxis. ${ }^{14}$ These authors recommended antibiotic prophylaxis before RFA intervention plus a prolonged course for at least 10 days postprocedure. ${ }^{14}$ However, given the small sample size, more convincing evidence is required to support the use of prophylaxis.

Shin et al. revealed that the time from TACE to diagnosis of HA ranged from 2-90 days, and the median survival time after this diagnosis was 6 months. ${ }^{10}$ This finding illustrates the importance of monitoring patients for signs of infection post procedure and early detection and treatment of $\mathrm{HA}$.

\section{Iatrogenic Abscess}

In addition to TACE and RFA, several other procedures have been associated with an increased risk of HA formation. The incidence of HA following biliary procedures has been 
Mavilia M.G. et al: Evolving nature of hepatic abscess

reported to be up to $26 \% .^{2}$ Biliary stenting, sphincterotomy, and EBA are known to contaminate the biliary tract with bacteria, ${ }^{38}$ allowing for ascending infection. ${ }^{42}$ Matthews et al. reported that HA after a biliary procedure tended to be more indolent compared to those from biliary obstruction. ${ }^{33}$

Surgical procedures on the hepatobiliary system can disturb the liver's blood supply, ${ }^{33}$ leading to ischemic necrosis. Similarly, arterial embolization used in the treatment of abdominal trauma can also cause ischemic necrosis of the liver and subsequent abscess formation. ${ }^{2}$ In addition, complications of surgical procedures, such as biliary stricture, can result in secondary infection of susceptible tissues. ${ }^{33}$

Choledochoduodenostomy can be complicated by "sump syndrome, ${ }^{\prime 43}$ in which bile flow through a segment of the surgically altered common bile duct become stagnant. ${ }^{43}$ This complication contributes to bacterial proliferation and predisposes patients to cholangitis and $\mathrm{HA} .{ }^{43}$

Blunt trauma and some surgical procedures can produce hematomas in the liver. Although hematoma is a rare complication of laparoscopic cholecystectomy, Brown et al. described a case in which a large hematoma on computed tomography (CT) was found on postoperative day 6 with early signs of infection. ${ }^{44}$ The development of hematoma during laparoscopic cholecystectomy may have been associated with prior use of nonsteroidal anti-inflammatory medications. ${ }^{44}$

\section{Diagnosis}

Because most of the symptoms of $\mathrm{HA}$ are due to infection and are nonspecific, ${ }^{2,17}$ it can be quite difficult to diagnose in a timely manner.

The most commonly reported signs and symptoms (Table 2) include fever in most but not all cases, abdominal pain, and hypotension. ${ }^{2,5,16,17,45-47}$ The percentage of patients affected by each symptom encompasses a fairly wide range, which reflects the high degree variability in clinical findings.

The difficulty in making the diagnosis is also reflected in the reported delay in time of onset of symptoms to time of diagnosis, which on average is one week. ${ }^{17}$

Laboratory findings in patients with $\mathrm{HA}$ are also relatively nonspecific. The most common abnormalities (Table 3) are elevated white blood cell count (WBC), elevated C-reactive protein, hypoalbuminemia, elevated aspartate aminotransferase (AST), elevated alanine aminotransferase (ALT), elevated alkaline phosphatase (ALP), elevated gamma glutamyl transpeptidase (GGT), elevated bilirubin, and elevated international normalized ratio (INR). ${ }^{17}$

While laboratory testing alone is not diagnostic, ${ }^{47}$ laboratory abnormalities usually prompt imaging studies that do lead to the diagnosis.

Diagnosis of HA is made by imaging in $90 \%$ of cases. ${ }^{2}$ Imaging can also help identify the underlying cause in some cases. ${ }^{2}$ The primary methods of diagnostic imaging are conventional ultrasound (US) and CT. Both methods carry a sensitivity of $96 \%-100 \%$ for detection of HA. ${ }^{47}$ However, Lin et al. found that $25 \%$ of patients had equivocal results in the emergency department, and $14 \%$ had a false negative result on US. ${ }^{25} \mathrm{HA}$ are typically hypo-echoic on US and may have varying degrees of internal echogenicity depending on the presence of septations or gas (Fig. 3). ${ }^{47}$

When US is nondiagnostic, CT, magnetic resonance imaging (MRI), or contrast enhanced US (CEUS) should be used to make the diagnosis. ${ }^{25}$ HAs have lower attenuation compared to normal liver tissue on noncontrast CT. ${ }^{47}$ With intravenous
Table 2. Clinical findings

Signs and symptoms

\begin{tabular}{ll}
\hline Malaise $^{16}$ & $89 \%$ \\
Chills $^{47}$ & $69 \%$ \\
Fever $^{17,46,47}$ & $59 \%-90 \%$ \\
Tachycardia $^{17}$ & $52 \%$ \\
Nausea $^{46,47}$ & $43 \%-68 \%$ \\
Abdominal pain $^{16,17,46}$ & $39 \%-84 \%$ \\
Vomiting $^{45,47}$ & $30 \%-32 \%$ \\
Right pleural effusion $^{45}$ & $28 \%$ \\
Weight loss $^{47}$ & $26 \%$ \\
Jaundice $^{17,47}$ & $19 \%-21 \%$ \\
Ascites $^{16,46}$ & $18 \%-21 \%$ \\
Murphy's sign $^{16}$ & $16 \%$ \\
Hepatomegaly $^{16,46}$ & $16 \%-52 \%$ \\
Guarding $^{17}$ & $14 \%$ \\
Respiratory distress $^{16}$ & $13 \%$ \\
Hypotension $^{16,17,46}$ & $13 \%-30 \%$ \\
Diarrhea $^{47}$ & $11 \%$ \\
Anorexia $^{16}$ & $11 \%$ \\
\hline
\end{tabular}

(IV) iodinated contrast, CT can reveal rim enhancement and enhancing internal septations, if present, due to increased vascularity of the abscess wall and septa. ${ }^{47}$ On MRI, HA will be hyperintense on T2-weighted images and hypointense on noncontrast T1-weighed images. Depending on the proteinaceous content of the HA, some may demonstrate hyperintense signal on noncontrast T1-weighted images. After the administration of gadolinium, HAs demonstrate similar enhancement characteristics seen with CT.

Although CEUS is not Food and Drug Administration (FDA)approved for liver imaging in the United States, it can be useful

Table 3. Laboratory findings

\begin{tabular}{ll}
\hline Abnormal laboratory finding $^{*}$ & \\
\hline C-reactive protein & $100 \%$ \\
Hemoglobin & $82 \%$ \\
Bilirubin & $75 \%$ \\
GGT & $75 \%$ \\
WBC & $74 \%$ \\
ALT & $73 \%$ \\
Albumin & $73 \%$ \\
ALP & $71 \%$ \\
AST & $67 \%$ \\
INR & $13 \%$ \\
\hline
\end{tabular}

*Adapted from Pang TC, Fung T, Samra J, Hugh TJ, Smith RC. Pyogenic liver abscess: an audit of 10 years' experience. World J Gastroenterol 2011;17:16221630. doi:10.3748/wjg.v17.i12.1622.

Abbreviations: ALP, alkaline phosphatase; ALT, alanine aminotransferase; AST, alanine aminotransferase; GGT, gamma glutamyl transpeptidase; INR, international normalized ratio; WBC, white blood cell count. 

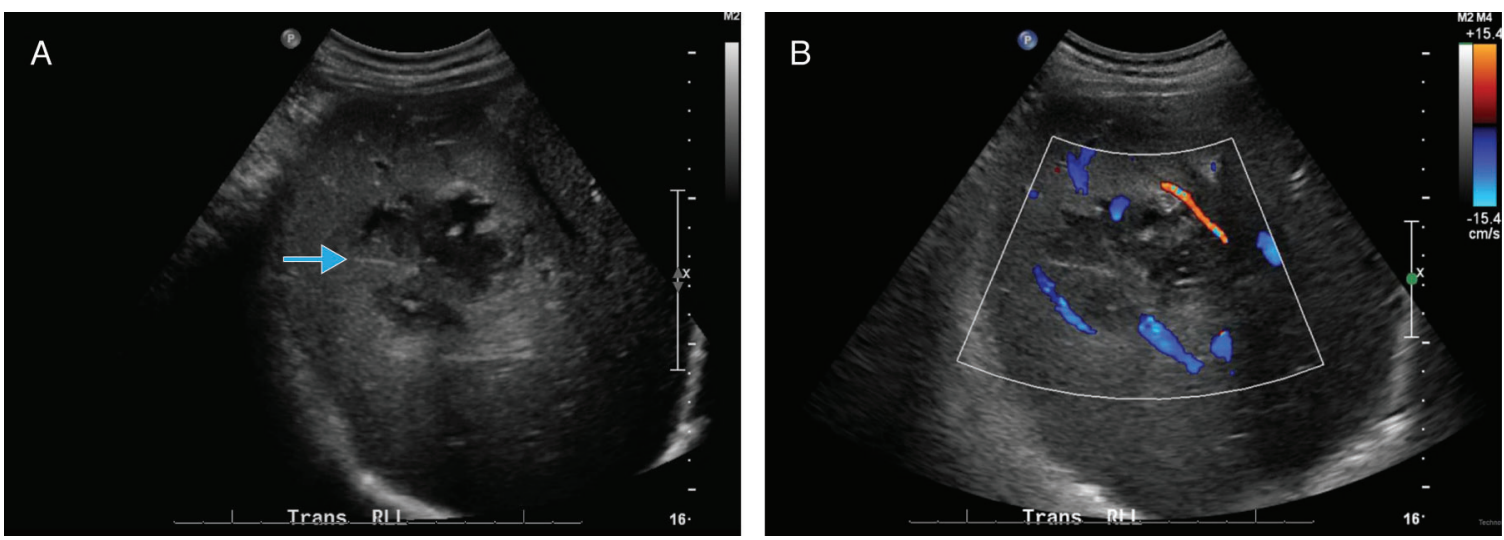

Fig. 3. Ultrasound (US). A. US demonstrates a hypoechoic abscess with heterogeneous echogenicity centrally consistent with septations and internal debris (blue arrow). B. Color Doppler US demonstrates peripheral hypervascularity surrounding the abscess cavity.

in the diagnosis of HA. CEUS is performed by injection of contrast medium through a peripheral IV line and subsequent views are taken through the arterial phase (10-30s postinjection), the portal phase (30-120s postinjection), and the late phase ( $>120 \mathrm{~s}$ postinjection). ${ }^{48}$ Many studies have identified characteristic features of HA on CEUS, including rim enhancement in the arterial phase, ${ }^{48,49}$ enhancement of septa creating a honeycomb appearance in loculated $\mathrm{HAs}^{48,49}$ and washout of the lesion during the late phase. ${ }^{48}$ A study by Popescu et al. evaluated 41 patients with confirmed $\mathrm{HA}$ for these three findings using CEUS. ${ }^{48}$ They concluded that CEUS yielded a "conclusive diagnosis" in $93 \%$ of cases and suggested that this method may be superior to conventional US. ${ }^{48}$ However, by using only patients with a confirmed diagnosis of HA, this study was not well controlled. In contrast, Liu et al. examined patients with various focal liver lesions, including $H A$, infected granulomas, and inflammatory pseudotumors. ${ }^{50}$ Like Popescu et al., Liu et al. demonstrated the same three characteristic findings in $\mathrm{HA}$, with $93.8 \%$ having rim enhancement, $68.8 \%$ showing septal enhancement, and $80.6 \%$ demonstrating late phase washout. ${ }^{50}$ However, this study also found rim enhancement in $20 \%$ of infected granulomas and $50 \%$ of the pseudotumor cases. ${ }^{50}$ Additionally, all of the infected granulomas and pseudotumors demonstrated late phase washout. ${ }^{50}$ These latter findings make it difficult to use these three characteristics findings as criteria for a "definitive diagnosis" as suggested by Popescu et al. Although the diagnostic value of CEUS may be slightly overstated by some authors, it is well described in the literature as providing clearer images than conventional US. ${ }^{51}$ CEUS allows for better visualization of the septations and consistency within the abscess, ${ }^{48,49 ., 51}$ which may better inform selection of a treatment approach.

These imaging techniques also play a role in diagnostic US or CT-guided needle aspiration, which can confirm the diagnosis of $\mathrm{HA}$ as the material sampled during this procedure can be analyzed to determine the etiological agent. This procedure also plays a therapeutic role in percutaneous drainage, which will be discussed later.

Other important features that can be observed from imaging studies include location, size, number of abscesses, consistency, and presence of gas within the abscess. The right lobe of the liver is the most common location, ${ }^{16,47}$ accounting for $68.7 \%$ of cases in one study. ${ }^{16}$ Solitary abscesses (Fig. 4) are more common than multiple abscesses (Fig. 5), represent- ing $67 \%-95 \%$ and $18 \%-32 \%$ of cases, respectively. ${ }^{16,17,52}$ With regard to consistency, abscesses were solid in $58 \%$ of cases and cystic in $42 \%$ of cases. ${ }^{52}$ Furthermore, gas was present in about $17 \%$ of cases. ${ }^{52}$ These radiological features can help both with classification of $\mathrm{HA}$ and selection of the most appropriate treatment approach. Improvements in imaging techniques have led to more efficient diagnosis and decreased mortality. ${ }^{53,54}$

\section{Treatment}

Prior to 1980, treatment of HA primarily consisted of open surgical drainage. ${ }^{54}$ However, percutaneous drainage (PD) has gained much popularity since its advent in $1953^{55}$ and has emerged as the first line treatment for HA. ${ }^{2,56}$ Smaller abscesses have even been managed medically with antibacterial therapy alone. ${ }^{2,54}$ The development of effective antibiotics and advances in minimally invasive procedures by interventional radiology have largely been responsible for the decrease in mortality rate of HA. ${ }^{17,52}$

\section{Medical management}

Management with antibiotics alone has been shown to be effective for small abscesses, $<3-5 \mathrm{~cm}$ in diameter. ${ }^{2}$ Hope et al. reported a $100 \%$ success rate for eight patients with unilocular abscess measuring $<3 \mathrm{~cm}$ in diameter with antibiotics alone. ${ }^{54}$ In a larger study of 176 patients, an $81.2 \%$ success rate after antibacterial treatment was reported. ${ }^{57}$ However, abscess characteristics, such as size and loculation, were not clearly stated in this group.

Biksup et al. proposed that smaller abscesses in difficult anatomical positions, such as in the caudate lobe, may be best treated conservatively due to the increased risks associated with invasive management. ${ }^{58}$

Antibacterial therapy should begin as soon as blood has been obtained for identification of organisms. ${ }^{2}$ Patients are typically treated initially with IV antibiotics, followed by a course of oral (PO) antibiotics. Recommendations for duration range from 3 weeks IV plus $1-2$ months PO to 2-3 weeks IV plus 1-2 weeks PO. ${ }^{47}$ Treatment duration depends on both response to treatment, as determined by repeat US imaging, and resolution of fever and leukocytosis. ${ }^{47}$

Empiric coverage for gram-negative bacilli, gram-positive cocci, as well as anaerobic bacteria has been recommended. ${ }^{2}$ 

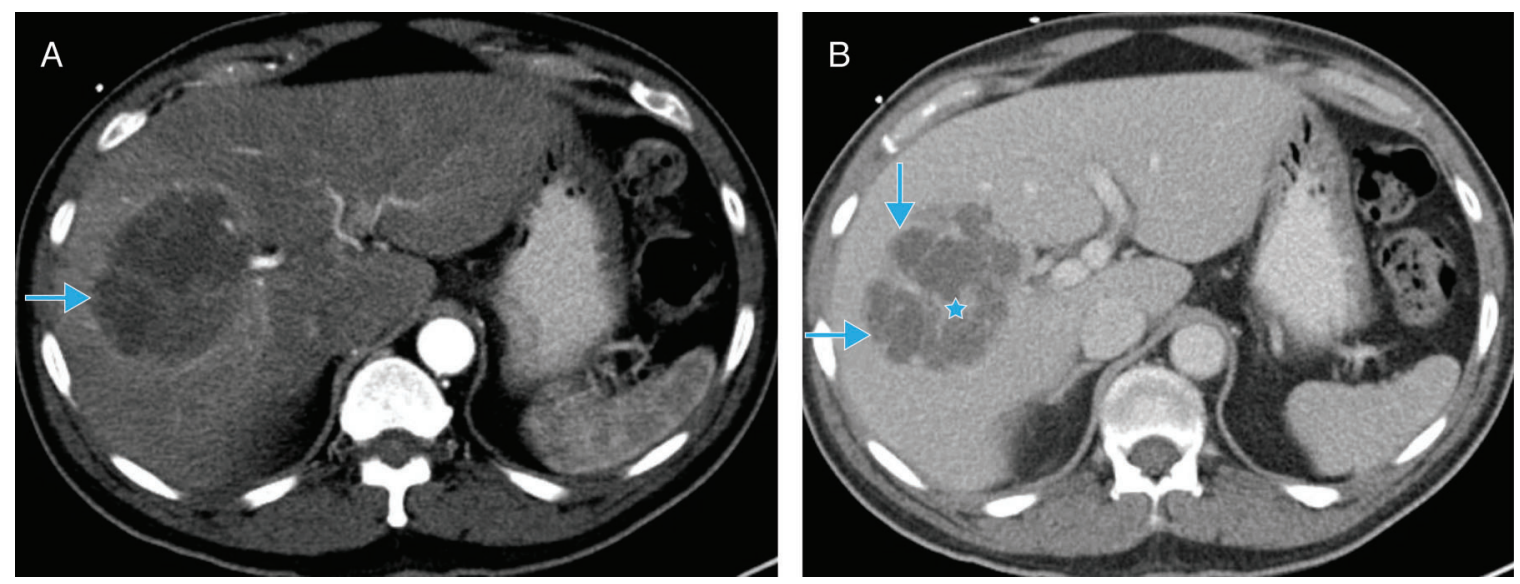

Fig. 4. Dynamic contrast-enhanced computed tomography (CT). A. Late arterial phase CT demonstrates hypervascular, peripheral enhancement of the abscess seen in Figure 4 (blue arrow). B. Portal venous phase CT demonstrates conspicuity of internally enhancing septations (blue star), likely representing intervening hepatic parenchyma. Note the multilocular nature of the abscess, which has implications for potential treatments (blue arrows).

This is usually accomplished with eithera third-generation cephalosporin plus metronidazole or piperacillin/tazobactam. ${ }^{47,53}$ However, some common pathogens associated with HA are resistant to both ampicillin and the fluoroquinolones. ${ }^{47}$ Treatment is becoming complicated as the incidence of a hyperresistant $K$. pneumonia increases in some parts of the world. ${ }^{47}$

\section{Interventional treatment}

PD is the most commonly selected option for first-line treatment of HA. HA can be drained either with needle aspiration or by insertion of a pigtail catheter drain under US or CT guidance. ${ }^{2}$ With percutaneous needle aspiration, a $16-18 \mathrm{Ga}$ needle is inserted into the abscess cavity, and contents are aspirated until it is evacuated completely. ${ }^{56}$ Similarly, during percutaneous catheter drainage, an 8-14 F pigtail catheter is inserted into the lesion and left in place. ${ }^{56}$ It is then drained by gravity until empty. ${ }^{56}$ Several studies have found percutaneous catheter drainage to be more effective than percutaneous needle aspiration, as it has higher success rates. ${ }^{56,59}$

PD carries many benefits, including being a minimallyinvasive procedure, ${ }^{53,54}$ obviating the need for general anesthesia. ${ }^{53,54,60}$ It also has a lower risk of adhesion formation, contamination, and a relatively lower cost compared to surgical drainage (SD). ${ }^{60}$

It has been reported that PD fails in $15 \%-36 \%$ of cases. ${ }^{17,45}$ There are a few possible reasons for these failures. HAs that are multiloculated can pose a challenge to drain all compartments. ${ }^{53,54}$ In addition, HAs containing viscous fluid and necrotic tissue may be difficult to drain completely $45,53,54$ due to blockage of the catheter. ${ }^{45,53}$ Pang et al. found that hypoalbuminemia was a significant risk factor for PD failure. ${ }^{17}$ The reason for this increase in risk is somewhat unclear. However, a low albumin level may indicate severity of any underlying sepsis. ${ }^{17}$ In spite of its minimal invasiveness, PD has been reported to be complicated by hemorrhage and biliary fistulae. ${ }^{17}$

\section{Surgical treatment}

Surgery is indicated as the initial management for HA rupture, ${ }^{53,54}$ peritonitis, ${ }^{17}$ anatomically difficult access, ${ }^{43,54}$ and co-existing pathology requiring surgery. ${ }^{53,54}$ Initial surgical management may also be indicated for larger abscesses measuring $>3-5 \mathrm{~cm}$ in diameter. ${ }^{53,54}$ However, some controversy remains in the literature regarding the best approach for treatment of large abscesses.
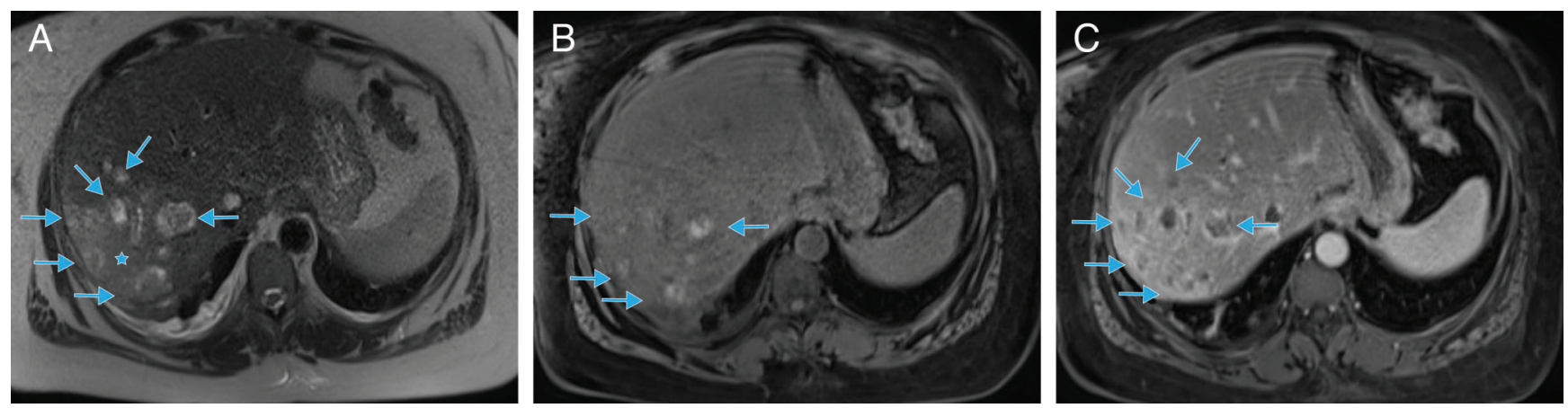

Fig. 5. Magnetic resonance imaging (MRI). A. T2-weighted image demonstrates multiple (at least six) small hyperintense abscess cavities in the right hepatic lobe (blue arrows). Note the hyperintense, edematous hepatic parenchyma (blue star). B. Noncontrast T1-weighted fat-sat image demonstrates varying degrees of T1 hyperintensity in the abscess cavities consistent with proteinaceous debris. C. Postcontrast T1-weighted fat-sat image demonstrates peripheral or rim enhancement around each of the abscesses. 


\section{Interventional versus surgical treatment}

Since 2001, the number of interventional drainage procedures has more than doubled, while the number of surgical drainage procedures has decreased by about $20 \% .{ }^{60}$ Selection of a treatment method depends largely on the size and consistency of the abscess. One study of 48 patients with large $(>3 \mathrm{~cm})$, unilocular abscesses treated with PD plus antibiotics reported an $83 \%$ success rate. ${ }^{54}$ Large, multiloculated HAs treated with PD and antibiotics had only a $33 \%$ success rate, whereas a large multi-loculated group treated by SD was $100 \%$ successful. ${ }^{54}$ Comparison of these findings with findings from similar studies is shown in Table 4. This study, among others, demonstrated better clinical outcomes with SD for patients with larger abscesses. ${ }^{53,54}$ However, Ferraioli et al. demonstrated similar success rates of $95.4 \%$ and $93.4 \%$ for PD and SD, respectively. ${ }^{46}$ Data for the SD group in Ferraioli's study was collected during an earlier time period (beginning in 1981) than the PD group (1998), and changes in medical imaging and management during this time may have impacted the results. In addition, both Ferraioli et al. and Tan et al. allocated patients to either a PD or SD group based on clinical judgment of the treating physician. ${ }^{46,53}$ Hope et al. defined the study groups by abscess size alone. ${ }^{54}$ This difference may account for some of the discrepancy in success rates between these three studies.

When selecting a treatment approach, it is important to consider the morbidity and mortality of these procedures. In the past, SD has been associated with a high mortality rate, ranging from $10 \%-47 \% .{ }^{56}$ One might expect this finding to be true as patients selected for surgery are typically those with larger abscesses, difficult anatomic access, multiple comorbidities, or other complicating factors. In comparing the modalities, many studies have found no significant difference in mortality between PD and SD. ${ }^{46,53,54}$ However, Ferraioli et al. found that the SD group had a significantly higher morbidity (9.1\%) compared to the PD group (0\%). ${ }^{46}$ In contrast, Tan et al. found no significant difference in morbidity between these two groups. ${ }^{53}$ It is likely that the difference in sample size and relative distribution between treatment groups accounted for the different findings of these two studies.

\section{Other considerations in selecting the treatment approach}

In addition to abscess size and consistency, the type of abscess should be considered when choosing a treatment strategy (Fig. 6). Several reports recommended that iatrogenic abscesses due to surgical procedures should be treated surgically. ${ }^{2}$ In addition, because malignant HAs containing necrotic tissue are at higher risk for PD failure, ${ }^{45}$ malignant abscesses may be less likely to respond to PD. Nevertheless, because PD is minimally invasive, it might be reasonable to attempt PD if accessible, and only if unsuccessful, resort to SD. 46,47

\section{Complications}

It has been reported that $15.7 \%$ of patients develop complications from HA. ${ }^{16}$ This includes septic metastasis leading to extrahepatic complications, such as endopthalmitis, ${ }^{16,61}$ septic pulmonary embolism, ${ }^{52}$ infection of the lungs, central nervous system, and the eyes. ${ }^{47}$ Abscess rupture is another reported complication, ${ }^{16}$ with spontaneous rupture occurring in $6.1 \%$ of cases. ${ }^{52}$ There was a higher reported incidence of $\mathrm{HA}$ rupture in abscesses infected with Klebsiella compared to other bacteria. ${ }^{47} \mathrm{HAs}$ can also erode the diaphragm, causing pleural effusion, empyema, pneumonia, pericarditis, bronchopleural fistulas, or duodenobronchofistulas. ${ }^{36}$ Multiorgan failure can also occur as a consequence of HA. ${ }^{16}$

Table 4. Treatment success rates

\begin{tabular}{|c|c|c|c|}
\hline \multicolumn{4}{|l|}{ Treatment } \\
\hline Study & Medical & Radiological & Surgical \\
\hline Alkofer et al. ${ }^{45} 2011$ & $\begin{array}{l}70 \% \\
\mathrm{n}=17 \\
\text { Mean diameter } 3.7 \mathrm{~cm}\end{array}$ & $\begin{array}{l}75.4 \% \\
\mathrm{n}=57 \\
\text { Mean diameter } 8.7 \mathrm{~cm}\end{array}$ & $\begin{array}{l}91.6 \% \\
\mathrm{n}=12 \\
\text { Mean diameter } 9.14 \mathrm{~cm}\end{array}$ \\
\hline Ferraioli et al. ${ }^{46} 2008$ & - & $\begin{array}{l}95.4 \% \\
\mathrm{n}=108 \\
\text { Mean diameter } 5.1 \mathrm{~cm}\end{array}$ & $\begin{array}{l}93.2 \% \\
\mathrm{n}=44 \\
\text { Mean diameter } 5.3 \mathrm{~cm}\end{array}$ \\
\hline \multirow[t]{2}{*}{ Hope et al. ${ }^{54} 2008$} & $\begin{array}{l}100 \% \\
\mathrm{n}=8 \\
\text { Diameter }<3 \mathrm{~cm}\end{array}$ & $\begin{array}{l}83 \% \\
\mathrm{n}=48 \\
\text { Diameter }>3 \mathrm{~cm} \\
\text { Uni-locular }\end{array}$ & $\begin{array}{l}100 \% \\
\mathrm{n}=27 \\
\text { Diameter }>3 \mathrm{~cm} \\
\text { Multi-locular }\end{array}$ \\
\hline & & $\begin{array}{l}33 \% \\
\mathrm{n}=24 \\
\text { Diameter }>3 \mathrm{~cm} \\
\text { Multilocular }\end{array}$ & \\
\hline Tan et al. ${ }^{53} 2005$ & - & $\begin{array}{l}72.2 \% \\
\mathrm{n}=36 \\
\text { Diameter }>5 \mathrm{~cm}\end{array}$ & $\begin{array}{l}93.8 \% \\
\mathrm{n}=44 \\
\text { Diameter }>5 \mathrm{~cm}\end{array}$ \\
\hline Bamberger et al. ${ }^{57} 1996$ & $\begin{array}{l}81.2 \% \\
n=176\end{array}$ & - & - \\
\hline
\end{tabular}


Mavilia M.G. et al: Evolving nature of hepatic abscess

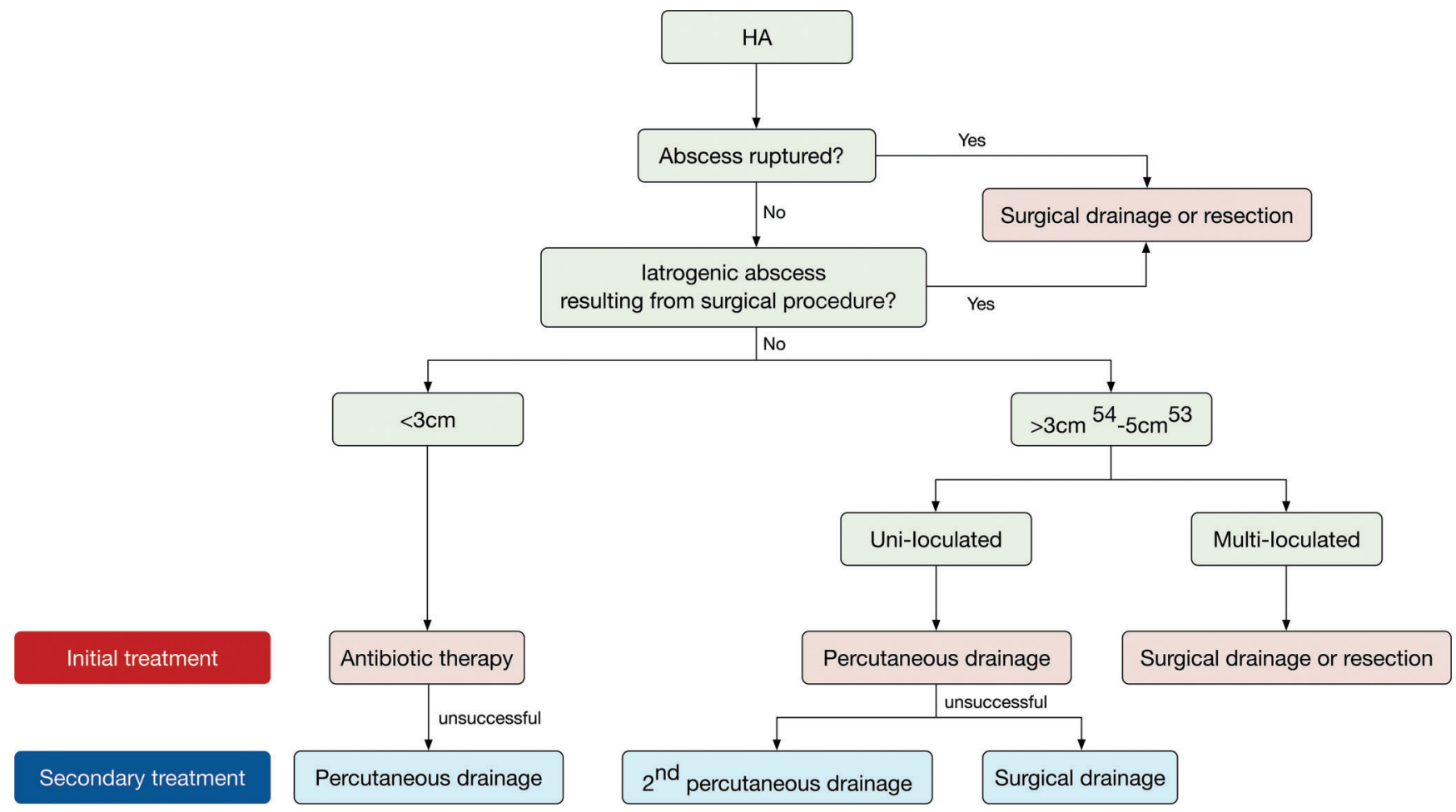

Fig. 6. Treatment strategies of HA*.

*Adapted from Hope WW, Vrochides DV, Newcomb WL, Mayo-Smith WW, lannitti DA. Optimal treatment of hepatic abscess. Am Surg 2008;74:178-182.

\section{Conclusions}

Despite its low incidence, $\mathrm{HA}$ is associated with a relatively high mortality rate and several serious complications. For these reasons, prompt recognition is important in instituting effective management and achieving good outcomes. Because of the nonspecific symptoms and laboratory findings, the presence of predisposing factors can be helpful in increasing the level of diagnostic suspicion. Radiological features can help with both classification of HA and selection of the most appropriate treatment approach. Depending on its characteristics, HA can be effectively treated by either PD or SD in combination with antibiotics. The key to successful outcomes with both approaches is early diagnosis and institution of appropriate therapy. More prospective trials with large cohorts are needed to refine our understanding of this serious condition.

\section{Acknowledgements}

This work was made possible by the Herman Lopata Chair in Hepatitis Research.

\section{Conflict of interest}

None

\section{Author contributions}

Drafted the manuscript (MGM), analyzed the images for figures and revisions (MM), proposed the concept of the review and revised the manuscript with critical revisions (GYW).

\section{References}

[1] Yu Y, Guo L, Hu C, Chen K. Spectral CT imaging in the differential diagnosis of necrotic hepatocellular carcinoma and hepatic abscess. Clin Radiol 2014;69: e517-e524. doi: 10.1016/j.crad.2014.08.018

[2] Lardière-Deguelte $S$, Ragot $E$, Armoun $K$, Piardi T, Dokmak S, Bruno O, et al. Hepatic abscess: diagnosis and management. J Visc Surg 2015;152: 231-243. doi: 10.1016/j.jviscsurg.2015.01.013

[3] Keller J], Tsai MC, Lin CC, Lin YC, Lin HC. Risk of infections subsequent to pyogenic liver abscess: a nationwide population-based study. Clin Microbiol Infect 2013;19:717-722. doi: 10.1111/1469-0691.12027

[4] Huang CJ, Pitt HA, Lipsett PA, Osterman FA, Lillemoe KD, Cameron JL, et al. Pyogenic hepatic abscess. Changing trends over 42 years. Ann Surg 1996; 223:600-607. doi: 10.1097/00000658-199605000-00016

[5] Lee KT, Wong SR, Sheen PC. Pyogenic liver abscess: an audit of 10 years' experience and analysis of risk factors. Dig Surg 2001;18:459-465, discussion 465-466. doi: 10.1159/000050194

[6] Murarka S, Pranav F, Dandavate V. Pyogenic liver abscess secondary to disseminated streptococcus anginosus from sigmoid diverticulitis. J Glob Infect Dis 2011;3:79-81. doi: 10.4103/0974-777X.77300

[7] Kumar D, Ramanathan S, Al Faki A, Nepal P. Faecolith migrating from the appendix to produce liver abscess after subhepatic laparoscopic appendectomy. Trop Doct 2015;45:241-244. doi: 10.1177/0049475515577749

[8] Law ST, Li KK. Is hepatic neoplasm-related pyogenic liver abscess a distinct clinical entity? World J Gastroenterol 2012;18:1110-1116. doi: 10.3748/ wjg.v18.i10.1110

[9] Trump DL, Fahnestock R, Cloutier CT, Dickman MD. Anaerobic liver abscess and intrahepatic metastases: A case report and review of literature. Cancer 1978;41:682-686. doi: 10.1002/1097-0142(197802)41:2<682::AIDCNCR2820410237>3.0.CO;2-I

[10] Shin JU, Kim KM, Shin SW, Min SY, Park SU, Sinn DH, et al. A prediction model for liver abscess developing after transarterial chemoembolization in patients with hepatocellular carcinoma. Dig Liver Dis 2014;46:813-817. doi: 10. 1016/j.dld.2014.05.003 
[11] Huang SF, Ko CW, Chang CS, Chen GH. Liver abscess formation after transerterial chemoembolization for malignant hepatic tumor. Hepatogastroenerology 2003;50:1115-1118.

[12] Iida $\mathrm{H}$, Aihara T, Ikuta $\mathrm{S}$, Yamanaka N. Risk of abscess formation after liver tumor radiofrequency ablation: A review of 8 cases with a history of enterobiliary anastomosis. Hepatogastroenterology 2014;61:1867-1870.

[13] Elias D, Di Pietroantonio D, Gachot B, Menegon P, Hakime A, De Baere T. Liver abscess after radiofrequency ablation of tumors in patients with a biliary tract procedure. Gastreoenterol Clin Biol 2006;30:823-827. doi: 10 . 1016/S0399-8320(06)73327-9

[14] Hoffmann R, Rempp H, Schmidt D, Pereira PL, Claussen CD, Clasen S. Prolonged antibiotic prophylaxis in patients with bilioenteric anastomosis undergoing percutaneous radiofrequency ablation. J Vasc Interv Radiol 2012;23: 545-551. doi: 10.1016/j.jvir.2011.12.025

[15] Lin YT, Liu CJ, Chen TJ, Chen TL, Yeh YC, Wu HS, et al. Pyogenic liver abscess as the initial manifestation of underlying hepatocellular carcinoma. Am J Med 2011;124:1158-1164. doi: 10.1016/j.amjmed.2011.08.012

[16] Chen $\mathrm{CH}$, Wu SS, Chang $\mathrm{HC}$, Chang YJ. Initial presentations and final outcomes of primary pyogenic liver abscess: a cross-sectional study. BMC Gastroenterol 2014;14:133. doi: 10.1186/1471-230X-14-133

[17] Pang TC, Fung T, Samra J, Hugh TJ, Smith RC. Pyogenic liver abscess: An audit of 10 years' experience. World J Gastroenterol 2011;17:1622-1630. doi: 10.3748/wjg.v17.i12.1622

[18] Jeong SW, Jang JY, Lee TH, Kim HG, Hong SW, Park SH, et al. Cryptogenic pyogenic liver abscess as the herald of colon cancer. J Gastroenterol Hepatol 2012;27:248-255. doi: 10.1111/j.1440-1746.2011.06851.x

[19] Tian LT, Yao K, Zhang XY, Zhang ZD, Liang YJ, Yin DL, et al. Liver abscesses in adult patients with and without diabetes mellitus: an analysis of the clinical characteristics, features of the causative pathogens, outcomes and predictors of fatality: a report based on a large population, retrospective study in China. Clin Microbiol Infect 2012;18:E314-E330. doi: 10.1111/j.14690691.2012.03912.x

[20] Eltawansy SA, Merchant C, Atluri P, Dwivedi S. Multi-organ failure secondary to a Clostridium perfringens liver abscess following a self-limited episode of acute gastroenteritis. Am J Case Rep 2015;16:182-186. doi: 10.12659/ AJCR.893046

[21] Weng SW, Liu JW, Chen WJ, Wang PW. Recurrent Klebsiella pneumonia liver abscess in a diabetic patient followed by Streptococcus bovis endocarditis- Occult colon tumor plays an important role. Jpn J Infect Dis 2005 ; 58:70-72.

[22] Mølle I, Thulstrup AM, Vilstrup H, Sørensen HT. Increased risk and case fatality rate of pyogenic liver abscess in patients with liver cirrhosis: a nationwide study in Denmark. Gut 2001;48:260-263. doi: 10.1136/gut.48.2.260

[23] Lai SW, Lai HC, Lin CL, Liao KF. Splenectomy correlates with increased risk of pyogenic liver abscess: a nationwide cohort study in Taiwan. J Epidemiol 2015;25:561-566. doi: 10.2188/jea.JE20140267

[24] Wang YP, Liu CJ, Chen TJ, Lin YT, Fung CP. Proton pump inhibitor use significantly increases the risk of cryptogenic liver abscess: a population-based study. Aliment Pharmacol Ther 2015;41:1175-1181. doi: 10.1111/apt. 13203

[25] Lin AC, Yeh DY, Hsu YH, Wu CC, Chang H, Jang TN, et al. Diagnosis of pyogenic liver abscess by abdominal ultrasonography in the emergency department. Emerg Med J 2009;26:273-275. doi: 10.1136/emj.2007.049254

[26] Yeh TS, Jan YY, Jeng LB, Hwang TL, Chao TC, Chien RN, et al. Pyogenic liver abscess in patients with malignant disease: a report of 52 cases treated at a single institution. Arch Surg 1998;133:242-245. doi: 10.1001/archsurg. 133.3.242

[27] Jorge JF, Costa AB, Rodrigues JL, Girão ES, Luiz RS, Sousa AQ, et al. Salmonella typhi liver abscess overlying a metastatic melanoma. Am J Trop Med Hyg 2014;90:716-718. doi: 10.4269/ajtmh.13-0573

[28] Tsai MS, Lee HM, Hsin MC, Lin CL, Hsu CY, Liu YT, et al. Increased risk of pyogenic liver abscess among patients with colonic diverticular diseases: a nationwide cohort study. Medicine (Baltimore) 2015;94:e2210. doi: 10.1097/ MD.0000000000002210

[29] Qu K, Liu C, Wang ZX, Tian F, Wei JC, Tai MH, et al. Pyogenic liver abscesses associated with nonmetastatic colorectal cancers: An increasing problem in Eastern Asia. World J Gastroenterol 2012;18:2948-2955. doi: 10.3748/wjg. v18.i23.2948

[30] Lai HC, Chan CY, Peng CY, Chen CB, Huang WH. Pyogenic liver abscess associated with large colonic tubulovillous adenoma. World J Gastroenterol 2006; 12:990-992. doi: 10.3748/wjg.v12.i6.990

[31] Sucandy I, Gallagher S, Josloff RK, Nussbaum ML. Severe clostridium infection of liver metastases presenting as pneumoperitoneum. Am Surg 2012; 78:E338-E339.

[32] Gross RG, Reiter B, Korsten MA. Pyogenic liver abscess complicating colonoscopic polypectomy. Gastroinest Endosc 2008;67:767-768. doi: 10.1016/j. gie.2007.08.028

[33] Matthews JB, Gertsch P, Baer HU, Blumgart LH. Hepatic abscess after biliary tract procedures. Surg Gynecol Obstet 1990;170:469-475.
[34] Lin JN, Lin CL, Lin MC, Lai CH, Lin HH, Kao CH. Pyogenic liver abscess in patients with inflammatory bowel disease: a nationwide cohort study. Liver Int 2016;36:136-144. doi: 10.1111/liv.12875

[35] Nakayama H, Takayama T, Hemmi A. Small necrotic liver metastasis with microscopic tumor embolism in hepatic vein: a case report and review of the literature. Int Surg 2005;90:293-296.

[36] Mercantini P, Virgilio E, Balducci G, Chieco PA, Romiti A, Di Rocco R, et al. Duodenobronchial fistula arising from a necrotizing liver metastasis of right colon cancer after systemic chemotherapy. Am Surg 2010;76: 1434-1436.

[37] Robertson RD, Foster JH, Peterson CG. Pyogenic liver abscess studied by cholangiography. Case report and 25-year review. Am Surg 1966;32: 521-530.

[38] Montvuagnard T, Thomson V, Durieux M, Mabrut JY, Marion-Audibert AM. Berthezene $Y$, et al. Superinfection of focal liver lesions after bile duct procedures. Diagn Interv Imaging 2012;93:e191-e195. doi: 10.1016/j.diii.2012. 01.001

[39] Sun Z, Li G, Ai X, Luo B, Wen Y, Zhao Z, et al. Hepatic and biliary damage after transarterial chemoembolization for malignant hepatic tumors: incidence, diagnosis, treatment, outcome and mechanism. Crit Rev Oncol Hematol 2011;79:164-174. doi: 10.1016/j.critrevonc.2010.07.019

[40] Shin SW. The current practice of transarterial chemoembolization for the treatment of hepatocellular carcinoma. Korean J Radiol 2009;10:425-434. doi: $10.3348 / \mathrm{kjr} .2009 .10 .5 .425$

[41] Morimoto M, Numata K, Kondo M, Moriya S, Morita S, Maeda S, et al. Radiofrequency ablation combined with transarterial chemoembolization for subcapsular hepatocellular carcinoma: a prospective cohort study. Eur J Radiol 2013;82:497-503. doi: 10.1016/j.ejrad.2012.09.014

[42] Huang RJ, Ambrosy AP, Triadafilopoulos G. Hepatic abscess with biliary communication following transarterial chemoembolization of hepatocellular carcinoma. Dig Dis Sci 2013;58:2463-2465. doi: 10.1007/s10620-0132593-1

[43] Hiura A, Kim EC, Ikehara T, Matsumura Y, Mishima K, Ishida I. Hepatic abscess as a complication of the sump syndrome. J Hepatobiliary Pancreat Surg 2000;7:231-235. doi: 10.1007/s005340050182

[44] Brown V, Martin J, Magee D. A rare case of subcapsular liver haematoma following laparoscopic cholecystectomy. BMJ Case Rep 2015;2015. doi: $10.1136 /$ bcr-2015-209800

[45] Alkofer B, Dufay C, Parienti J], Lepennec V, Dargere S, Chiche L. Are pyogenic liver abscesses still a surgical concern? A Western experience. HPB Surg 2012;2012:316013. doi: 10.1155/2012/316013

[46] Ferraioli G, Garlaschelli A, Zanaboni D, Gulizia R, Brunetti E, Tinozzi FP, et al. Percutaneous and surgical treatment of pyogenic liver abscesses: observation over a 21-year period in 148 patients. Dig Liver Dis 2008;40:690-696. doi: 10.1016/j.dld.2008.01.016

[47] Lübbert C, Wiegand J, Karlas T. Therapy of liver abscesses. Viszeralmedizin 2014;30;334-341. doi: 10.1159/000366579

[48] Popescu A, Sporea I, Sirli R, Dănilă M, Mare R, Grădinaru Taşcău O, et al. Does contrast enhanced ultrasound improve the management of liver abscesses? A single centre experience. Med Ultrason 2015;17:451-455.

[49] Catalano O, Sandomenico F, Raso MM, Siani A. Low mechanical index contrast-enhanced sonographic findings of pyogenic hepatic abscesses. AJR Am J Roentgenol 2004;182:447-450. doi: 10.2214/ajr.182.2.1820447

[50] Liu G], Lu MD, Xie XY, Xu HX, Xu ZF, Zheng YL, et al. Real-time contrastenhanced ultrasound imaging of infected focal liver lesions. J Ultrasound Med 2008;27:657-666.

[51] Kishina M, Koda M, Tokunaga S, Miyoshi K, Fujise Y, Kato J, et al. Usefulness of contrast-enhanced ultrasound with Sonazoid for evaluating liver abscess in comparison with conventional B-mode ultrasound. Hepatol Res 2015;45: 337-342. doi: 10.1111/hepr.12347

[52] Chang Z, Zheng J, Ma Y, Liu Z. Analysis of clinical and CT characteristics of patients with Klebsiella pneumoniae liver abscesses: an insight into risk factors of metastatic infection. Int J Infect Dis 2015;33:50-54. doi: 10 . 1016/j.ijid.2014.12.041

[53] Tan YM, Chung AY, Chow PK, Cheow PC, Wong WK, Ooi LL, et al. An appraisal of surgical and percutaneous drainage for pyogenic liver abscesses larger than $5 \mathrm{~cm}$. Ann Surg 2005;241:485-490. doi: 10.1097/01.sla.0000154265. 14006.47

[54] Hope WW, Vrochides DV, Newcomb WL, Mayo-Smith WW, Iannitti DA. Optimal treatment of hepatic abscess. Am Surg 2008;74:178-182.

[55] McFadzean AJ, Chang KP, Wong CC. Solitary pyogenic abscess of the liver treated by closed aspiration and antibiotics. Br J Surg 1953;41:141-152. doi: $10.1002 /$ bjs.18004116606

[56] Cai YL, Xiong XZ, Lu J, Cheng Y, Yang C, Lin YX, et al. Percutaneous needle aspiration versus catheter drainage in the management of liver abscess: a systematic review. HPB (Oxford) 2015;17:195-201. doi: 10.1111/hpb.12332

[57] Bamberger DM. Outcome of medical treatment of bacterial abscesses without therapeutic drainage: review of cases reported in the literature. Clin Infect Dis 1996;23:592-603. doi: 10.1093/clind/23.1.592 
Mavilia M.G. et al: Evolving nature of hepatic abscess

[58] Biskup E, Yang XY. Pyogenic hepatic abscess- less is more. A review for general internists. Praxis (Bern 1994) 2015;104:1091-1095. doi: 10.1024/ 1661-8157/a002155

[59] Zerem E, Hadzic A. Sonographically guided percutaneous catheter drainage versus needle aspiration in the management of pyogenic liver abscess. AJR Am J Roentgenol 2007;189:W138-W142. doi: 10.2214/AJR. 07.2173
[60] Levin DC, Eschelman D, Parker L, Rao VM. Trends in use of percutaneous versus open surgical drainage of abdominal abscesses. J Am Coll Radiol 2015;12:1247-1250. doi: 10.1016/j.jacr.2015.06.015

[61] Cheng DL, Liu YC, Yen MY, Liu CY, Wang RS. Septic metastatic lesions of pyogenic liver abscess. Their association with Klebsiella pneumoniae bacteremia in diabetic patients. Arch Intern Med 1991;151;1557-1559. doi: 10. 1001/archinte.1991.00400080059010 